\title{
THE BICHLORIDE SITUATION.
}

$\mathrm{O}$ RDINARILY the stream of Council business, as reported in the letters which are issued between meetings, flows with scarcely a ripple of debate. This is not because the Councilors are inattentive to the letters or are afraid to express their opinions in opposition, but rather because propositions of a controversial nature are generally held for consideration at the annual meeting, and the questions submitted for mail vote are usually of a formal kind not calculated to provoke debate. Council Letter No. 13, which appears in this issue, and in which Chairman Hugh Craig, of the Section on Education and Legislation, and President George M. Beringer discuss the advisability of adopting a specific shape for bichloride or other highly poisonous tablets, presents an interesting exception to the usual order.

$\mathrm{Mr}$. Craig contends, and his contention is undoubtedly correct, that the frequent cases of alleged accidental poisoning with bichloride tablets are not accidental in fact, but that the tablets are taken with suicidal intention. $\mathrm{He}$ also argues that if a person is bent upon self-destruction he will certainly accomplish his purpose, no matter how many restrictions be placed upon the dispensing of poisons, and further, that peculiar shapes or colors for dangerous tablets will not operate as warnings to children.

$\mathrm{Mr}$. Craig's remedy would be to restrict the dispensing of mercury bichloride to physicians' prescriptions, coupled with restrictions which would prevent physicians from leaving such tablets with patients without cautionary wrappings.

Undoubtedly such restrictions would lessen the number of poisonings from bichloride, but this raises the question as to the extent to which such restrictions should be placed upon other poisonous compounds generally and upon dealers other than druggists. If we are to restrict the sale of mercuric bichloride to physicians' prescriptions, why not place the same restrictions upon all drugs which can be used suicidally or which may be taken by mistake for less dangerous ones? And if such restrictions are to be placed upon articles dispensed from drug stores, why should they not be placed equally upon dangerous substances for sale at the paint store or elsewhere? Thoughtless people, while generally ready to applaud restrictions laid upon the druggist in the name of public safety, are generally strongly opposed to legislation that would prevent their obtaining poisonous insecticides and other substances used in agriculture or the arts.

Some years ago the writer, in a paper presented at one of the meetings of this Association, called attention to several state laws which placed heavy penalties upon druggists for selling poisons without certain precautions of labeling and registration, but leaving it open to all other dealers of the state to sell the same articles without restriction. Even at the present time there is a bill pending in Congress greatly limiting the manner in which registered physicians and druggists may sell or dispense mercury bichloride, but not placing any limitation whatever upon its sale by other persons.

Unless we are careful in the endorsement of restrictive legislation, we shall some day awaken to the fact that the druggist is bound hard and fast, while the 
paint stores, hardware stores, and other dealers in insecticides are free to sell equally dangerous substances practically without restriction.

The teaching of this is that, since it would be manifestly impossible to restrict the sale of all dangerous poisons to physicians' prescriptions, and manifestly unfair to place such restrictions upon the druggist and leave all other dealers free, then the next best thing, and the thing which is altogether feasible and capable of universal application is to require the indication of the poisonous character of dangerous compounds by appropriate labels, shapes and colors of packages, or other warnings which would appeal to the senses of those who might otherwise handle the articles carelessly. For the would-be suicide, of course, no warning would suffice.

Whatever restrictions are adopted should apply equally to all dangerous substances as well as to those usually handled by the druggist, and to all dealers and distributors alike.

As to the wisdom of the Association's taking over the assignment of the patent which has been applied for by the Norwich Pharmacal Company, on coffin-shaped tablets of mercury bichloride, several considerations present themselves.

If the Association accepts the assignment, it would, of course, accept it simply as a trustee for the public welfare. It would permit all manufacturers to use the design without charge, and would exercise its rights as owner of the patent only in case some one should presume to make use of the design in a freak confection.

If the Association does not accept the assignment tendered by the Norwich Pharmacal Company, the latter will be entitled to prevent any rival manufacturer from using the same design unless licensed for that purpose.

It should be borne in mind that the granting of a patent for a coffin-shaped tablet would not prevent the patenting or copyrighting of other designs, and also that final decision as to what designs shall be lawful or unlawful will remain with the law-making powers.

City councils, state legislatures, and Congress will be besieged constantly for the enactment of bichloride legislation, and will undoubtedly take action. We may protest against such legislation until we are out of breath, without avail. Ordinances and laws will be adopted by the dozen, and no two of them will be alike or in correspondence unless we can set a national standard, as for example, by the adoption by the Pharmacopoia of a specific, or perhaps of several permissible designs, which can be cited for the guidance of the various legislative bodies.

We cannot stop the flood of bichloride legislation, but we can to a large extent direct it into safe and practical channels; and this it seems to me, is the discreet and politic thing to do. 